Check for updates

Newcastle University

Cite this as: $B M J 2021 ; 375: n 3121$ http://dx.doi.org/10.1136/bmi.n3121 Published: 20 December 2021

\title{
The future doctor and the future patient-reaching a true partnership
}

\section{David J Hunter emeritus professor of health policy and management}

The growing crisis in the NHS adds greater urgency to our efforts to create a future doctor-patient relationship that is both equal and effective. The current arrangement is no longer fit for purpose, if it ever was, with patients often left feeling disempowered. ${ }^{1}$ Too often, efforts to engage the public and patients in their health have amounted to symbolic gesturing, with plans for hospitals and practices excluding their voices.

Such hubristic activity has been termed "engagement camouflage" for decisions that are still largely taken elsewhere without patient or public input. In a classic study 50 years ago, the American political scientist Robert Alford referred to patients and the public as "repressed interests," while doctors remained the "dominant interests." 2 Little has changed over the years, although with the arrival of managers and managerialism (the "challenging interests"), doctors may feel themselves to hold less sway than they once did.

\section{The patient as a consumer}

Since the 1990 until very recently, the focus in the NHS has been on choice and competition as proxies for creating a true partnership between doctors and the public and patients. Choice and competition were central planks in successive English governments' health reforms despite the contested nature of their alleged virtues. As studies have shown, most patients and the public didn't really want choice-rather, they wanted accessible services provided locally where possible that they could trust and which were safe and of good quality. 34

For the most part, the focus on choice and competition only served to reinforce the idea of patients as consumers and largely passive ones at that. But we are now entering a new era of health reform marked by another "C" word-collaboration. The move towards integrated care systems (ICSs) in England, which will join up local services, offers a fresh opportunity to foster a true partnership between the public, patients, and doctors. This can be summed up by the term co-production.

As Tudor Hart put it presciently in 1994: "recognition of patients as co-producers rather than consumers would begin to solve several problems which are otherwise only likely to get worse. As co-producers, patients must share much more actively both in defining their problems and in devising feasible solutions than they have in the past." 5 There is no place in co-production for outmoded notions of professional dominance or paternalism, but instead a focus on combining the respective strengths of the public and professions.

\section{A new approach to tackling inequality}

As has been well documented, covid-19 cruelly exposed weaknesses in our health system. ${ }^{6-8}$ None of these were new, but they were not always widely appreciated or thought to be too catastrophic in terms of their impact on the people and communities marked by high levels of deprivation and widening inequalities. We now know differently.

In particular, the pandemic showed how critical public health is and yet how impoverished it has become-especially since 2010, when austerity cuts began to fall on public services and in particular those provided by local government. ${ }^{9}$ The consequence has been a reduction in life expectancy in many parts of the country. ${ }^{9}$

When considering the future doctor-patient relationship, it merits framing in a broader context than is customary when focusing on doctors and patients as individuals. The pandemic has shown how place and communities are pivotal in fashioning an effective response to the risks to people's health, both physical and mental. As we seek to give higher priority to population health and to tackling health inequalities, there is a need to include the public and the places they inhabit in any true partnership between doctors and patients. A key test of success for ICSs will be the extent to which this ambition is realised.

Such a focus requires doctors to be less reactive and to ask what our communities' most important health needs are and then to tackle them in conjunction with citizens and patients - that is, through co-production. The priority for the future doctor is their relationship with the community, not just that between doctor and patient. If such a system can work in a country like Costa Rica, which has put public health centre stage with impressive results (life expectancy is almost 81 years at a fraction of the healthcare costs of high income countries), it can surely work for a UK city or region too. ${ }^{10}$ Costa Rica has achieved these gains in life expectancy by seeding its public health efforts to protect health and prevent disease in local communities.

A new way of working is called for that does not place all the power in the hands of hospitals and advanced specialties. Those active in primary care and in public health in local government need to be at the centre of integrated care. Citizens need to also be given a more pronounced role in the ICS reforms now being implemented. And I don't mean "tick box" patient engagement exercises of the kind we've become all too familiar with over the years, but an insistence on citizen panels being introduced into ICS decision making. 


\section{Cultural change}

We've already tried following where the values of choice and competition led us, and that didn't work for patients and the public or doctors. Going forward, collaboration and co-production offer hope for a new compact, or social contract, between the public, patients, and doctors. But it will only succeed through cultural rather than structural change, which focuses on changing behaviour and developing new relationships and ways of interacting.

Competing interests: none declared.

Provenance and peer review: Not commissioned; not peer reviewed.

1 Williamson C. Patients' emancipation: towards equality. Quacks Books, 2021.

2 Alford RR. Health care politics. Chicago University Press, 1975.

3 Audit Commission and Healthcare Commission. Is the treatment working? Progress with the NHS system reform programme. Audit Commission, 2008.

4 Fotaki M, Boyd L, Smith R, et al. Patient choice and the organisation and delivery of health services: scoping review. Report for the NCCSDO. 2006. Manchester: Centre for Public Policy and Management.

5 Tudor Hart J. Feasible socialism: the NHS past, present and future. Socialist Health Association, 1994.

6 Marmot M, Allen J, Boyce T, Goldblatt P, Morrison J. Health equity in England: the Marmot review 10 years on. Institute of Health Equity, 2020, https://www.instituteofhealthequity.org/resourcesreports/marmot-review-10-years-on.

7 Marmot M, Allen J, Goldblatt P, Herd E, Morrison J. Build back fairer: the covid-19 Marmot review: the pandemic, socioeconomic and health inequalities in England. Institute of Health Equity, 2020, http://www.instituteofhealthequity.org/resoucres.reports/build-back-fairer-the-covid-19-marmotreview.

8 Marteau TM, Rutter H, Marmot M. Changing behaviour: an essential component of tackling health inequalities. BMJ2021;372:n332. doi: 10.1136/bmj.n332. pmid: 33568384

9 Lewer D, Bibby J. Cuts to local government funding and stalling life expectancy. Lancet Public Health 2021;6:e623-4. doi: 10.1016/S2468-2667(21)00136-5. pmid: 34265264

10 Gawande A. Costa Ricans live longer than we do. What's the secret? The New Yorker. 23 August 2021. 